\title{
Why candidate divergence should be expected to be just as great (or even greater) in competitive seats as in non-competitive ones
}

\author{
James Adams • Thomas L. Brunell • Bernard Grofman • \\ Samuel Merrill, III
}

Received: 17 November 2008 / Accepted: 16 November 2009 / Published online: 22 December 2009

(C) The Author(s) 2009. This article is published with open access at Springerlink.com

\begin{abstract}
Basic Downsian theory predicts candidate convergence toward the views of the median voter in two-candidate elections. Common journalistic wisdom, moreover, leads us to expect these centripetal pressures to be strongest when elections are expected to be close. Yet, the available evidence from the US Congress disconfirms this prediction. To explain this counterintuitive result, we develop a spatial model that allows us to understand the complex interactions of political competition, partisan loyalties, and incentives for voter turnout that can lead office-seeking candidates, especially candidates in close elections, to emphasize policy appeals to their voter base rather than courting the median voter.
\end{abstract}

Keywords Spatial models · Candidate polarization · US politics

\section{Introduction}

Downs (1957) offered a simple model that highlighted the power of centripetal ideological pressures in two-party competition. Many US government textbooks now treat this model as something like gospel: e.g., symbolically presenting candidates as archers aiming for the winning bull's-eye, i.e., for dead center. However, the simplest Downsian model also posits that all elections will be competitive, since candidates will converge to identical policy positions and thus, given pure policy voting, should be equally likely to gain voter support.

\author{
J. Adams (凶) \\ Department of Political Science, University of California at Davis, Davis, CA, USA \\ e-mail: jfadams@ucdavis.edu \\ T.L. Brunell \\ The School of Policy Science, University of Texas at Dallas, Richardson, TX, USA \\ B. Grofman \\ Department of Political Science, University of California at Irvine, Irvine, CA, USA
}

S. Merrill, III

Department of Mathematics and Computer Science, Wilkes University, Wilkes-Barre, PA, USA 
Yet, we know that this implication of the basic Downsian model is at odds with the empirical evidence. Over the past three decades there has been a huge amount of theoretical work on parties' election strategies that attempts to illuminate this discrepancy.

The present state of the art suggests that convergence (or, at least full convergence) in two-party competition is extremely unlikely from a theoretical perspective (see extended reviews in Grofman 2004; Adams et al. 2005; Miller and Schofield 2004). A campaign strategy, furthermore, focused on swing voters near the median of the voter distribution is both costly-because such voters include many who are apolitical and poorly motivated to vote - and problematic — because, unlike citizens in the base, swing voters may vote for either side. Moreover, empirical research on this topic provides compelling evidence of divergence, e.g., between US Senators of the same state (Poole and Rosenthal 1984), or House members elected from a given district who came from opposite parties. For example, Ansolabehere et al. (2001), applying the scaling methodology of Heckman and Snyder (1997) to data over the period 1874-1996, find that congressional candidates "have primarily espoused the ideology associated with the national party, moderating very little to accommodate local ideological conditions" (p. 136). Adams et al. (2004) find that, controlling for voters' partisan loyalties and other variables, the vote shares of US Senate candidates increase as they take stands that diverge from the center of their state's voter distribution in the direction of their partisan constituencies, while Kenny and Lotfinia (2005) and Schmidt et al. (1996) report research on senate and presidential elections that supports the hypothesis that candidates derive electoral benefits in general elections from appealing on policy grounds to their partisan constituencies. Similar non-convergence results are found in Snyder (1994); Erikson and Wright (1997, 2000); Burden (2001); Lee et al. (2004); and Clinton (2006).

However, we might expect that the degree of candidate accommodation to the local electorate would vary with the level of political competition. The key intuition is that representatives from safe seats should be able to more safely disregard the views of independents and minority party voters in their constituencies than can representatives from marginal seats. Hence, regardless of what might be the case in non-competitive seats, when elections are expected to be very close it still seems plausible that candidates of each party will moderate their positions toward those of the median voter in the district. The notion that safe seats should produce more extreme candidates than competitive ones is a widely held view among American journalists, as shown in this quote from a story in the New York Times: "The increasing partisan use of redistricting means that there are fewer swing districts in the US House, thus fewer lawmakers in the middle" (Toner 2004). ${ }^{1}$ On the other hand, this is not the common wisdom outside the United States, even in countries that also use pluralitybased single member district elections. Consider, for example, this quote: "In voting in the British House of Commons, the more marginal the seat, the more extreme the position" (Baughman 2004).

It is certainly conceivable that we can have extremism positively correlated with competition in the British Parliament, but the exact opposite relationship in the US House of Representatives. But another possibility is that the assertion in the New York Times linking swing seats in the US House to legislator moderation is simply, as a matter of empirical fact, wrong. Indeed, there is a very recent body of political journalism in the United States suggesting that, when confronted with (potentially) very close contests, instead of reaching out to centrist voters, candidates may now seek to mobilize their own support base in terms of

\footnotetext{
${ }^{1}$ Over the last decade or so, language much like the New York Times quote above could be found in op-ed columns throughout the US.
} 
turnout and campaign support by espousing non-centrist positions which are especially attractive to their own party's supporters. Moreover, recent empirical work finds that, while, in the US House "competition exerts some pressure on candidates to fit with their constituents ... that degree of responsiveness waned in the 1980s and 1990s" (Ansolabehere et al. 2001, p. 36).

We present a neo-Downsian model to explain the patterns that scholars such as Ansolabehere et al. (2001) identify, namely the absence of a clear positive link between district competitiveness and candidate convergence. We model the complex interactions of political competition, partisan loyalties, and incentives for voter turnout to try to understand when office-seeking candidates, especially candidates in close elections, will take positions far from the district median, thereby seeking to mobilize their voter base to turn out by adopting positions attractive to the party faithful, rather than appealing to the median voter by moving towards the center. The consequences of our model are assessed by a combination of analytic and computer simulation techniques. Our work is part of a recent tradition of modifying classic Downsian assumptions in order to produce more empirically realistic outcomes. $^{2}$ In particular, we extend the theoretical work of Adams et al. (2005, Chaps. 7-8), that analyzes candidates' strategic responses to partisan bias and the threat of abstention.

The centripetal "pull" of the median voter is widely viewed as the most important factor that tethers office-seeking candidates near the center of the voter distribution. But, research into political behavior has long offered reason to question the dominance of spatial considerations, instead drawing attention to voting decisions driven by partisan ties or candidate features (see, e.g., Campbell et al. 1960 and the vast literature following). Our results point to a revised understanding of the interplay of strategic candidate positioning, party reputation, and electoral choice. ${ }^{3}$ We show that, even in highly competitive races, and for electorates that include substantial proportions of independents, office-seeking candidates have substantial incentives to appeal to their partisan constituencies. ${ }^{4}$

\section{A model of voter choice and turnout}

A number of models have been developed to explain divergent strategies. Callander and Wilson (2006) obtain a divergent equilibrium, assuming abstention due to alienation and the threat of third party entry (see also Palfrey 1984). Schofield and Sened $(2005,2006)$ investigate divergence in a multiparty context. Butler (2006) develops a model that assumes that partisans support their party for non-policy reasons but may abstain if the candidate is too far toward the center and that swing voters vote in a Downsian fashion. Using districtlevel estimates of the voter distribution, he explains polarization among candidates in terms

\footnotetext{
${ }^{2}$ See, also Aldrich (1995); Erikson and Romero (1990), Roemer (2001), Schofield and Sened (2006), Peress (2008), Serra (2008). Work by Groseclose and Snyder (2000), Erikson and Wright (2000), and Clinton et al. (2004) has addressed Congressional elections in particular.

${ }^{3}$ The results of our modeling are also consistent with important experimental work by Van Houweling and Sniderman (2005) that explores how voters' partisan loyalties alter the logic of the Downsian space. These authors suggest that the constraints of the median voter are less stringent than have been supposed, and that partisan elites have more-although not limitless-freedom of maneuver than has been appreciated (Van Houweling and Sniderman 2005, p. 3).

${ }^{4}$ They also follow without recourse to arguments based on centrifugal considerations created by the need to appeal to party activists for campaign support or to raise money, or considerations of future support for higher office by the party hierarchy.
} 
of the location and size of candidates' bases and proportions of swing voters and focuses on change over time as these variables have changed.

Here we extend the development in Adams et al. (2005), which depends on abstention due to alienation and on partisan bias of voters to address the question of how partisan divergence varies with district competitiveness. We analyze a two-candidate election involving a Democratic candidate $D$ and a Republican candidate $R$, who choose positions along a unidimensional Liberal-Conservative ideological continuum. The candidates' positions are denoted by $D$ and $R$, respectively. Voters' utilities for the candidates are based on a simple version of the behavioral researcher's multivariate voting model, one in which voters are influenced by three factors: their proximities to the candidates' ideological positions; their partisan loyalties; and, a random variable representing unmeasured influences on the vote. Thus a voter $i$ 's utilities for candidates $D$ and $R$, denoted $U_{i}(D)$ and $U_{i}(R)$, respectively, are given by:

$$
\begin{aligned}
& U_{i}(D)=-a\left(x_{i}-D\right)^{2}+b p_{i D}+\varepsilon_{i D}=V\left(x_{i}, D\right)+\varepsilon_{i D}, \\
& U_{i}(R)=-a\left(x_{i}-R\right)^{2}+b p_{i R}+\varepsilon_{i R}=V\left(x_{i}, R\right)+\varepsilon_{i R},
\end{aligned}
$$

where $a$ is the salience of ideology, $x_{i}$ is voter $i$ 's ideological position, $p_{i D}$ and $p_{i R}$ are dummy variables that equal 1 if $i$ identifies with the candidate's party and zero otherwise, $b$ represents the salience of party identification, and $\varepsilon_{i D}$ and $\varepsilon_{i R}$ are random disturbance terms. We further represent the deterministic components of utility as $V\left(x_{i}, D\right)$ and $V\left(x_{i}, R\right)$. We specify that $a>0$ and $b \geq 0$, i.e., that voter utilities decline with the ideological distance to the candidate, and that partisanship cannot bias the voter against his party's candidate. This latter specification encompasses both the standard spatial model in which partisanship does not influence voters $(b=0)$ and the more general case in which partisanship biases the voter in favor of his party's candidate $(b>0)$.

Our specification, that the voter's party identification influences her evaluations of the candidates independently of her ideological position, is supported by empirical research on presidential elections (Markus and Converse 1979; Alvarez and Nagler 1995, 1998), Congressional elections (McIver et al. 1993; Erikson and Wright 1997; Ansolabehere et al. 2001; Krasno 1994), and gubernatorial elections (Lacy and Paolino 1998). This finding is consistent with the "Michigan model" of voting (Campbell et al. 1960), in which partisanship is conceptualized as a long-term, affective orientation towards one's preferred party-one that grows out of early socialization experiences and positive evaluations of the party's past performance - and which is largely independent of the candidates' positions in the current election (see Fiorina 1981; Jennings and Niemi 1981; Green et al. 2002). Previous spatial modeling work by Erikson and Romero (1990), Adams et al. (2005, Chaps. 7-8), Butler (2006), and Peress (2008), analyzes American candidates' strategies in situations where voters display such partisan biases.

We assume that citizens' turnout decisions depend on whether they find either of the candidates sufficiently attractive to turn out to vote. Specifically, let $T_{i}(A)$ represent voter $i$ 's alienation threshold, which is the minimum candidate utility such that $i$ prefers voting for the candidate to abstaining. We specify this threshold as a function of a constant term, $A$, plus a random variable $\varepsilon_{i A}$ that depends on unmeasured, voter-specific, characteristics such as political efficacy, education, etc.:

$$
T_{i}(A)=A+\varepsilon_{i A}
$$


We assume that citizen $i$ votes for candidate $D$ if her utility for $D, U_{i}(D)$, exceeds both her utility for $R, U_{i}(R)$, and her alienation threshold $T_{i}(A)$; that she votes for $R$ if $U_{i}(R)$ exceeds $U_{i}(D)$ and $T_{i}(A)$; that otherwise she abstains.

Our vote-choice model is conditional logit, a model that has been used extensively in empirical voting studies (see Endersby and Galatas 1998; Burden and Lacy 1999; Merrill and Adams 2002). ${ }^{5}$ Under this model the probabilities $P\left(x_{i}, D\right), P\left(x_{i}, R\right)$, and $P\left(x_{i}, A\right)$ that voter $i$, located at position $x_{i}$, votes for $D$, votes for $R$, or abstains, respectively, are:

$$
\begin{aligned}
& P\left(x_{i}, D\right)=\frac{e^{V\left(x_{i}, D\right)}}{e^{V\left(x_{i}, D\right)}+e^{V\left(x_{i}, R\right)}+e^{A}}, \\
& P\left(x_{i}, R\right)=\frac{e^{V\left(x_{i}, R\right)}}{e^{V\left(x_{i}, D\right)}+e^{V\left(x_{i}, R\right)}+e^{A}},
\end{aligned}
$$

and

$$
P\left(x_{i}, A\right)=1-P\left(x_{i}, D\right)-P\left(x_{i}, R\right) .
$$

The turnout model we employ is a simplified version of the one developed by Lacy and Burden (1999), see also Burden and Lacy (1999), which they have applied to US presidential elections (see also Adams et al. 2006). Note that this model specifies that voter abstention is driven entirely by alienation from the candidates, rather than indifference between them. While empirical studies suggest that substantial numbers of American voters do indeed abstain due to alienation (see Adams et al. 2006; Brody and Page 1973; Guttman et al. 1994; Peress 2008), clearly this is a strong assumption. Nevertheless we employ this specification because we have found that incorporating abstention from indifference into the model greatly complicates our analysis of candidate strategies, but that-providing that alienation also contributes to abstention-it leaves our central substantive conclusions unchanged.

\section{Theoretical results: implications for candidate strategies}

We assume that the voter distribution consists entirely of three groups of citizens: a $D e$ mocratic constituency consisting of citizens who identify with the Democratic party, whose mean ideological position is $\mu_{D}$, a Republican constituency consisting of Republican partisans with mean ideological position $\mu_{R}$, and a set of independents whose mean position is $\mu_{I}$. The proportions of Democratic partisans, Republican partisans, and independents are given by $m_{D}, m_{R}$, and $m_{I}$, respectively, where $m_{D}+m_{R}+m_{I}=1$, and where $m_{D}$ and $m_{R}$ are strictly positive. We denote the mean voter location $\mu_{V}=\left(m_{D} \mu_{D}+m_{R} \mu_{R}+m_{I} \mu_{I}\right)$ as the center of the voter distribution, and without loss of generality we set $\mu_{V}=0$. We also assume that the mean location of independent voters is the same as the overall voter mean, i.e., that $\mu_{I}=0 .{ }^{6}$ We will look at how, via effects on the expected closeness of the election, candidate strategic behavior is affected by the size of each of these constituencies, and their respective degree of mobilization.

\footnotetext{
${ }^{5}$ Under conditional logit assumptions, the random component $\varepsilon$ associated with each alternative is generated independently from a type I extreme value distribution.

${ }^{6}$ Although this assumption apparently limits the generalizability of our model, a comparison of the overall voter means to the means of independents in US Senate elections, based on an analysis of voter survey data from the 50 US state electorates (data from the Pooled Senate Election Study, 1988-1992) suggests that this is a reasonable approximation for American state-level voter distributions.
} 
Adams et al. (2005, Chap. 7) present illustrative arguments that, in election contexts similar to the one described above, office-seeking candidates contesting general elections have incentives to diverge from the center of the voter distribution, in the direction of their partisan constituencies. Here we move beyond these illustrative arguments to present theoretical results on the existence and characteristics of candidates' Nash equilibrium strategies. Following previous spatial modeling studies with variable voter turnout, we assume that both candidates select positions that maximize their expected vote margins over their opponent (Hinich and Ordeshook 1970; Anderson and Glomm 1992). ${ }^{7}$ Candidate D's expected margin over $R, \operatorname{EM}(D)$, is given by the sum over all voters of the following expression:

$$
E M(D)=P(x, D)-P(x, R)=\frac{e^{V(x, D)}-e^{V(x, R)}}{e^{V(x, D)}+e^{V(x, R)}+e^{A}} .
$$

Theorem 1 (The Partisan Polarization Result) When the candidates select their positions from a finite set of platforms $Z$ that includes the platforms $D_{0}$ and $R_{0}$ whose positions are given by (1)-(2) below, then, for a sufficiently small and positive value of the policy salience coefficient $a$, the equilibrium configuration in candidates' margin-maximizing strategies is $\left(D_{0}, R_{0}\right)$, where

$$
\begin{aligned}
& D_{0}=c_{D} \mu_{D}, \quad \text { and } \quad c_{D}=\frac{e^{A}\left(e^{b}-1\right) m_{D}}{e^{A}\left(e^{b}-1\right) m_{D}+\frac{\left(e^{b}-1\right)^{2} m_{I}}{\left(2+e^{A}\right)}+\left(e^{A}+2 e^{b}\right)}, \\
& R_{0}=c_{R} \mu_{R}, \quad \text { and } \quad c_{R}=\frac{e^{A}\left(e^{b}-1\right) m_{R}}{e^{A}\left(e^{b}-1\right) m_{R}+\frac{\left(e^{b}-1\right)^{2} m_{I}}{\left(2+e^{A}\right)}+\left(e^{A}+2 e^{b}\right)} .
\end{aligned}
$$

Proof See in Appendix.

We now consider the question, what does Theorem 1 imply about the equilibrium strategies for margin-maximizing candidates? We note first that for the special case where $b=0$, i.e., when partisanship does not influence the vote, it follows from (1)-(2) that $c_{D}=c_{R}=0^{8}$ and hence that as $a \rightarrow 0$ both candidates' equilibrium positions will converge to the mean voter position, a result consistent with previous spatial modeling work with probabilistic voting and variable voter turnout (Enelow and Hinich 1989). However matters are quite different when voters exhibit partisan loyalties (i.e., $b>0$ ). In this situation it is easily verified from (1)-(2) that $0<c_{D}<1$ and $0<c_{R}<1,{ }^{9}$ and hence that as $a \rightarrow 0$ each candidate's equilibrium position diverges to a location between the mean voter position and the mean position of the candidate's partisan constituency. We therefore conclude that when voters display partisan biases and abstention is from alienation, each candidate's marginmaximizing position is shifted away from the center, in the direction of the mean position of the candidate's partisan constituency.

\footnotetext{
${ }^{7}$ All of the central substantive conclusions we report below carry through if instead we assume that candidates maximize their expected votes.

${ }^{8}$ This follows from the fact that when $b=0$, then the expression $\left(e^{b}-1\right)$ that appears in the numerator of (1) and (2) equals zero.

${ }^{9}$ To see this, note that in (1) and (2) the numerators are positive when $b>0$, while the denominators are equal to the numerator plus additional positive terms.
} 
More specifically, (1)-(2) imply that when voters display partisan biases (i.e., $b>0$ ) and $a \rightarrow 0$, the following relationships hold: First, ceteris paribus, the more extreme the position of the candidate's partisan constituency, the further the candidate diverges from the center, in the direction of this constituency. ${ }^{10}$ Second, again ceteris paribus, the larger the candidate's partisan constituency the further the candidate diverges from the center, in the direction of this constituency. ${ }^{11}$ Third, and again ceteris paribus, the larger the proportion of independent voters in the electorate the less the candidate diverges from the center, in the direction of her partisan constituency. ${ }^{12}$

Why, specifically, are margin-maximizing candidates motivated to shift away from the center, in the direction of their partisans? The reason is that the marginal change in a candidate's probabilities of attracting her own partisans' votes via policy appeals is higher than is the marginal change in her probabilities of attracting votes from the rival candidate's partisans. To understand why this is true, note that the properties of the conditional logit (CL) probability function imply that the weight $w_{i}$ that a candidate attaches to a voter $i$ 's policy preference increases as the probability that $i$ votes for the candidate approaches 0.5 (from either direction). ${ }^{13}$ This conforms to common sense: the more uncommitted the voter's decision to turn out to vote for a candidate, the more the candidate will take the voter's preferences into account (Erikson and Romero 1990, p. 1107). In a two-candidate election where voters have nonzero probabilities of abstaining, the higher of the voter $i$ 's two vote probabilities must be the one nearest 0.5 , and hence $i$ is most marginal with respect to the candidate that $i$ is most likely to support. Because, when $b>0$ and $a \rightarrow 0$, partisan voters are guaranteed to be more likely to vote for their party's candidate than for the opposition party's candidate, it follows that under these conditions candidates attach greater weight to the policy preferences of the members of their own partisan constituency than to the preferences of the members of the rival candidate's constituency.

To grasp the intuition outlined above without recourse to mathematics, consider the extreme situation where voters' partisan biases are so strong that they invariably prefer their party's candidate to the rival party's candidate, regardless of the candidates' positions, but where partisan voters are also prone to abstain, so that they turn out to vote only if they approve of their preferred candidate's policy position. In this scenario each candidate can influence the turnout decisions of the members of her own partisan constituency via her policy positioning, but the candidates cannot influence the behavior of the members of their rival's partisan constituency-since by construction the rival party's partisans invariably prefer the rival candidate and, furthermore, these partisans' turnout decisions depend solely on the rival candidate's positioning. Therefore in this hypothetical scenario each candidate's optimal strategy is to weight heavily the policy preferences of her own partisan constituency (along with the preferences of any independent voters in the electorate), while ignoring the policy preferences of the rival party's partisan constituency.

\footnotetext{
${ }^{10}$ This follows from the fact that the functions $c_{D}$ and $c_{R}$ are, by inspection, invariably positive when $b>0$.

${ }^{11}$ To see this, note that the numerator and the first expression in the denominator of (1)-(2) are each identical positive functions of the size of the candidate's partisan constituency $\left(m_{D}\right.$ or $\left.m_{R}\right)$, while the denominator contains additional positive terms.

${ }^{12}$ To see this, note that the proportion of independent voters $m_{I}$ appears only in the denominator of (1)-(2), and that in each case the denominator is a positive function of $m_{I}$. It follows that the values of $c_{D}, c_{R}$ decline as $m_{I}$ increases, which implies that the candidates converge towards the mean voter position as $m_{I}$ increases.

${ }^{13}$ This is also true for the multinomial probit probability function, in the general case where the correlations between the error terms associated with the candidates' utilities are set to zero, and the error terms have equal variances.
} 
Next, we relate (1)-(2) in Theorem 1 to the degree of candidate divergence:

Corollary to Theorem 1 (The Polarization Gap) For the conditions specified in Theorem 1 , then, for a fixed proportion $m_{I}$ of independent voters, the divergence between the candidates' equilibrium positions is greatest when the Democratic and Republican partisan constituencies are of equal size, i.e., when $m_{D}=m_{R}$, and the degree of candidate divergence declines monotonically as $\left(m_{D}-m_{R}\right)$ diverges from zero.

In words, this corollary states that the policy distance between the candidates' equilibrium positions increases as the proportions of Democratic and Republican partisans become more nearly equal, and that candidate divergence is maximized when there are equal proportions of Democratic and Republican partisans in the electorate, i.e., that candidate polarization is greatest when the election is most competitive. This corollary thereby directly contradicts the conventional wisdom that competitive elections motivate candidate convergence towards the center of the general electorate.

Why might candidates be most dispersed when the election is expected to be most competitive? The intuition can be grasped by considering the least competitive election context, namely that in which all citizens in the electorate identify with the same party. If, say, all citizens are Democratic partisans, then the Democratic candidate will appeal on policy grounds to these partisans, and so will the Republican candidate because she has no viable alternative strategy - since by construction there are no Republican partisans to whom this candidate can appeal. Therefore margin-maximizing candidates will converge to identical positions in this "perfectly" uncompetitive scenario, and, by extension, they can be expected to converge to similar positions for partisan contexts that strongly favor one party over the other. By contrast, in competitive districts, each candidate's optimal strategy is to appeal in large part to his/her own partisan constituency, which motivates increased divergence of the candidates' positions.

\section{Computational results}

While Theorem 1 and its corollary (the Polarization Gap) provide intuitions about candidate strategies, their empirical relevance is unclear because they apply only to elections where voters place limited weight on the candidates' policy positions. However Table 1 and Fig. 1 present computations on Nash equilibrium strategies-i.e., positions toward which we can expect office-seeking candidates to approach as they seek to maximize their expected vote margins over their opponent-for significantly positive values of the policy salience parameter. ${ }^{14}$ These optimal strategies are given for each party's candidate against systematic variation of the partisan composition of the electorate. In part A of the table (and of the figure) there are no independents; in part B independents comprise one third of the electorate. For the computations partisan distributions are assumed normally distributed on the conventional 1-7 scale, with the mean positions of the partisan constituencies set to $\mu_{D}=3$ for Democrats and $\mu_{R}=5$ for Republicans and the mean position for independents as $\mu_{I}=4$; standard deviations are set at $\sigma_{D}=\sigma_{R}=\sigma_{I}=1$. The policy salience coefficient is set to $a=0.25$ and the partisan salience coefficient to $b=2$, values that are consistent with empirical estimates on voting in US House elections (Stone and Simas 2008), US senate elections (Adams et al. 2004), and US presidential elections (Alvarez and Nagler 1995), when voters'

\footnotetext{
${ }^{14}$ These numerical calculations were adapted from the algorithm in Appendix 4.1 of Adams et al. (2005).
} 
Table 1 Candidate optima and vote share as a function of partisan decomposition of the electorate. Partisan distributions have equal variance: $\sigma_{D}=\sigma_{R}=1$

\begin{tabular}{llllllll}
\hline A. No independents & \multicolumn{7}{l}{} \\
\hline $\begin{array}{l}\text { Democratic } \\
\text { proportion }\end{array}$ & $\begin{array}{l}\text { Democratic } \\
\text { optima }\end{array}$ & $\begin{array}{l}\text { Republican } \\
\text { optima }\end{array}$ & $\begin{array}{l}\text { Divergence } \\
\text { of optima }\end{array}$ & $\begin{array}{l}\text { Democratic } \\
\text { vote-share } \\
(\%)\end{array}$ & $\begin{array}{l}\text { Republican } \\
\text { vote-share } \\
(\%)\end{array}$ & $\begin{array}{l}\text { Abstention } \\
(\%)\end{array}$ & $\begin{array}{l}\text { Democratic } \\
\text { percent of } \\
\text { voters }\end{array}$ \\
$(1)$ & $(2)$ & $(3)$ & $(4)$ & $(5)$ & $(6)$ & $(7)$ & $(8)$ \\
\hline $\mathbf{. 2}$ & $\mathbf{3 . 9 3}$ & $\mathbf{4 . 9 2}$ & 0.98 & 11.4 & 34.2 & 54.4 & 25.0 \\
$\mathbf{. 3}$ & $\mathbf{3 . 6 1}$ & $\mathbf{4 . 8 7}$ & 1.26 & 15.1 & 30.5 & 54.4 & 33.2 \\
$\mathbf{. 4}$ & $\mathbf{3 . 4 1}$ & $\mathbf{4 . 8 1}$ & 1.40 & 19.0 & 26.7 & 54.4 & 41.6 \\
$\mathbf{. 5}$ & $\mathbf{3 . 2 8}$ & $\mathbf{4 . 7 2}$ & 1.44 & 22.8 & 22.8 & 54.4 & 50.0 \\
$\mathbf{. 6}$ & $\mathbf{3 . 1 9}$ & $\mathbf{4 . 5 9}$ & 1.40 & 26.7 & 19.0 & 54.4 & 58.4 \\
$\mathbf{. 7}$ & $\mathbf{3 . 1 3}$ & $\mathbf{4 . 3 9}$ & 1.26 & 30.5 & 15.1 & 54.4 & 66.8 \\
$\mathbf{. 8}$ & $\mathbf{3 . 0 8}$ & $\mathbf{4 . 0 7}$ & 0.98 & 34.2 & 11.4 & 54.4 & 75.0 \\
\hline
\end{tabular}

B. Independents constitute one third of the electorate

\begin{tabular}{llllllll}
\hline $\begin{array}{l}\text { Democratic } \\
\text { proportion }\end{array}$ & $\begin{array}{l}\text { Democratic } \\
\text { optima }\end{array}$ & $\begin{array}{l}\text { Republican } \\
\text { optima }\end{array}$ & $\begin{array}{l}\text { Divergence } \\
\text { of optima }\end{array}$ & $\begin{array}{l}\text { Democratic } \\
\text { vote-share } \\
(\%)\end{array}$ & $\begin{array}{l}\text { Republican } \\
\text { vote-share } \\
(\%)\end{array}$ & $\begin{array}{l}\text { Abstention } \\
(\%)\end{array}$ & $\begin{array}{l}\text { Democratic } \\
\text { percent of } \\
\text { voters }\end{array}$ \\
\hline $\mathbf{. 2}$ & $(2)$ & $(3)$ & $(4)$ & $(6)$ & $(7)$ & $(8)$ \\
$\mathbf{. 3}$ & $\mathbf{3 . 9 6}$ & $\mathbf{4 . 7 9}$ & 0.83 & 10.6 & 25.4 & 64.0 & 29.4 \\
$\mathbf{. 4}$ & $\mathbf{3 . 7 3}$ & $\mathbf{4 . 7 3}$ & 1.00 & 13.0 & 23.0 & 64.1 & 36.1 \\
$\mathbf{. 5}$ & $\mathbf{3 . 5 6}$ & $\mathbf{4 . 6 6}$ & 1.10 & 15.4 & 20.4 & 64.1 & 43.0 \\
$\mathbf{. 6}$ & $\mathbf{3 . 4 3}$ & $\mathbf{4 . 5 7}$ & 1.14 & 17.9 & 17.9 & 64.1 & 50.0 \\
$\mathbf{. 7}$ & $\mathbf{3 . 3 4}$ & $\mathbf{4 . 4 4}$ & 1.10 & 20.4 & 15.4 & 64.1 & 57.0 \\
$\mathbf{. 8}$ & $\mathbf{3 . 2 7}$ & $\mathbf{4 . 2 7}$ & 1.00 & 23.0 & 13.0 & 64.1 & 63.9 \\
\hline
\end{tabular}

Notes: The model is conditional logit. Partisan distributions are assumed normally distributed on the conventional 1-7 scale, with $\mu_{D}=3$ and $\mu_{R}=5$, and standard deviations equal to 1 . Independents, if present, are normally distributed with mean $\mu_{I}=4$ and standard deviation equal to 1 . When independents are present, the Democratic proportion is the Democratic proportion of the partisans. The ideology-salience parameter, $a$, is set at 0.25 ; the partisan parameter $b$ is set to 2 ; and the (deterministic component $A$ of the) alienation threshold is set at 2

and candidates' ideological positions are calibrated along a 1-7 scale. ${ }^{15}$ The (deterministic component of the) alienation threshold, $A$, is set at 2, which implies that-realistically for congressional elections - about half or more of the potential electorate does not vote (see column 7 in Table 1).

\footnotetext{
${ }^{15}$ In fact, divergence of optimal strategies occurs for any plausible positive value of the partisan loyalty parameter $b$ (up to 10 times as high as the estimated value), for any plausible value of the parameter $A$ that specifies abstention due to alienation (up to almost complete abstention), and for any positive value of the ideology-salience parameter $a$. In addition, we note that the optimal strategies reported in Table 1 and Fig. 1, which are computed for realistic values of the ideology salience coefficient $a$, are similar to but even more divergent than the equilibrium locations given by (1)-(2) in Theorem 1, which are obtained theoretically for the special case in which $a$ approaches zero. For higher values of $a$, in the range $0.25<a<1.0$, the equilibrium configurations are similar to but more dispersed than those reported in Table 1.
} 
A. No independents

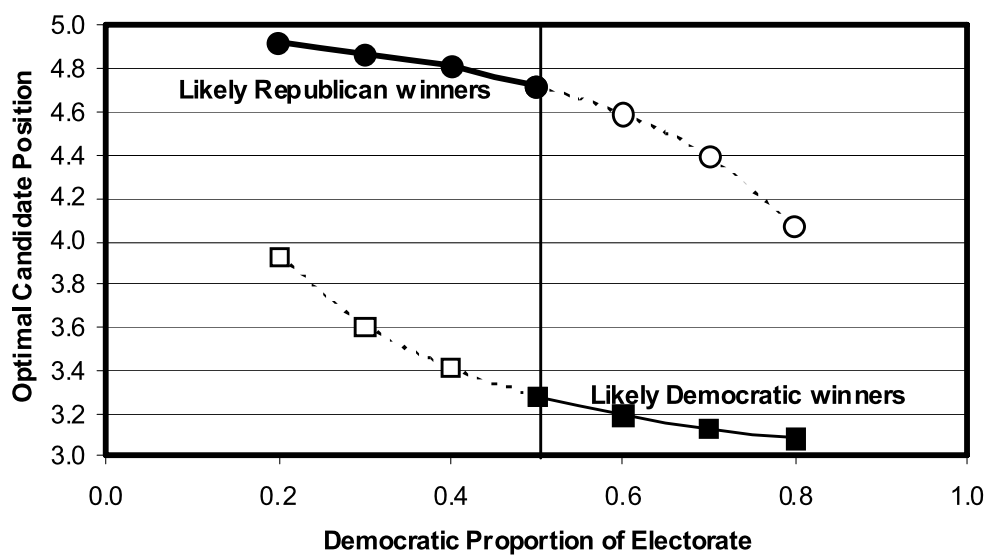

B. Independents constitute one third of the electorate.

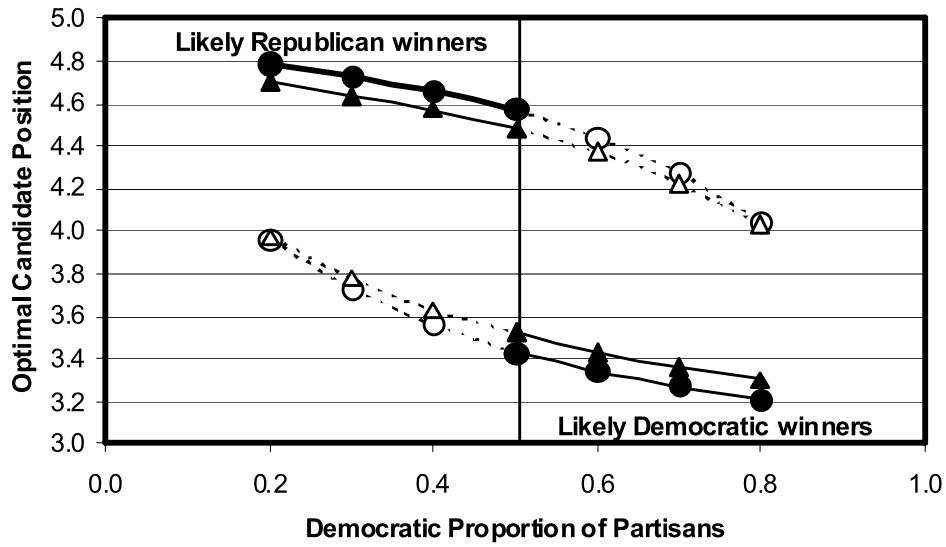

Fig. 1 Optimal candidate positions as a function of partisan decomposition of the electorate

Notes: Partisan distributions are assumed normally distributed on the conventional 1-7 scale, with $\mu_{D}=3$ and $\mu_{R}=5$ and standard deviations $\sigma_{D}=\sigma_{R}=1$. The ideology-salience parameter, $a$, is set at 0.25 ; the partisan parameter $b$ is set to 2 ; and the alienation threshold is set at 2 . Solid symbols indicate candidates whose expected vote-share (on a probabilistic basis) is at least 50 percent of the electorate, i.e., those candidates who are most likely to be elected. Open symbols indicate candidates less likely to win election. In part B, assumptions are the same as in part A, except that one third of the electorate are independents. For the curves with circular symbols, independents are assumed to have the same ideology-salience parameter $a$ as partisans; for those with triangular symbols, independents have no policy preferences. The horizontal axis denotes the Democratic proportion among partisans

Table 1 and Fig. 1 report computations that suggest that the substantive conclusions suggested by Theorem 1 and its corollary (The Polarization Gap) extend to these scenarios. Note first that for these computations we invariably located a unique equilibrium in margin-maximizing candidates' strategies. Furthermore, the computations suggest that the factors which cause the candidates' equilibrium positions to diverge for low degrees of pol- 
icy salience will exert similar effects for higher degrees of policy salience (represented by the policy salience parameter $a$ ): namely, the candidates' equilibrium positions diverge from the mean voter position in the direction of their partisan constituencies, and the degree of candidate divergence peaks when the candidates have equal-sized partisan constituencies, i.e., when the election is most competitive, and declines as the relative sizes of these partisan constituencies diverges, i.e., as the election becomes less competitive (see column 4 in Table 1). Note, in addition, that candidate divergence is less when there is a significant proportion of independent voters in the electorate (Table 1B) than when all voters are partisans (Table 1A). Thus, the values $D_{0}$ and $R_{0}$ appear to be good qualitative indicators of the equilibrium configuration; as $a$ increases, the configuration is similar but more dispersed.

\section{Discussion}

Although we provide arguments that party ID and abstention effects motivate divergence between Democratic and Republican candidates, we do not argue that these are the only possible explanations of partisan polarization. Candidates may need to hew to the national party line to get precious national party support, such as campaign funding, and to be accepted into the governing structure if they reach Congress or avoid retaliation in the form of being redistricted out of their seats. On the local as well as the national level, candidates may be drawn to more extreme positions by party activists, who tend to be more polarized than the general public (Schofield 2004; Miller and Schofield 2003). Alternatively, candidates may face opposition in primaries, which may induce them to adopt more extreme positions than would maximize votes in the general election (see Burden 2001; Polsby 1983; Key 1947; Owen and Grofman 2006; Adams and Merrill 2008).

Nonetheless, we have shown that, even in the absence of the considerations that most previous theorists have advanced to explain candidate divergence (i.e., the desire to appeal to special interest groups and party activists, the need to win primary elections, and so on), office-seeking candidates have incentives to diverge sharply from the center of the general electorate. Our theoretical and empirical results, which suggest that candidates can, under realistic conditions, maximize their vote margins in general elections by presenting policies designed to appeal to their partisan constituencies, is relevant to the extensive literature on elections and representation.

Dating back to Miller and Stokes's (1963) seminal work, scholars have conceptualized congressional representation in terms of the Miller-Stokes "diamond model" which emphasizes the linkages between legislators' roll-call votes and the policy preferences of their geographic constituencies, defined as the set of all voters from the legislator's district. However subsequent work has cast doubt on how well this diamond model captures the representational process; in particular, scholars have increasingly emphasized the crucial influence of the legislator's "reelection constituency" (Fenno 1978), defined as "the people who are reliable supporters at the ballot box" (Uslaner 1999, p. 12, emphasis in original). ${ }^{16}$

Uslaner summarizes the current state of the research as follows:

The [Miller-Stokes] model has served us well for a long time, but diamonds aren't forever... A more profound challenge to the diamond model comes from the recognition that legislators tend to represent their core supporters, mostly composed of their fellow partisans, better than they do the full electorate (Uslaner 1999, p. 12).

\footnotetext{
${ }^{16}$ Bishin's $(2000,2009)$ notion of electoral subconstituencies is also relevant here.
} 
The value of our theoretical results is that they provide a plausible rationale for the empirical finding that legislators tend to represent their core supporters at the expense of their geographic constituency: namely, that this is an electorally optimal strategy.

In addition, as we observed in the introduction to this essay, our emphasis on the centrifugal effects on candidate strategies associated with voter turnout in a partisan electorate is one that increasingly is shared, both by the popular media and by campaign managers (see Miniter 2005; Nagourney 2003; Millbank and Allen 2004). Thus Mathew Dowd, a senior advisor to George W. Bush's re-election campaign, stated in the summer of 2003 that "there's a realization, having looked at the past few elections, that the party that motivates their base - that makes their base emotional and turn out-has a much higher likelihood of success on election day" (quoted in Nagourney 2003). ${ }^{17}$ And Stanley Greenberg, a Democratic pollster who advised the Democratic presidential candidates Bill Clinton, Al Gore, and John Kerry, argues that in order to win elections

The starting point for both Democrats and Republicans is to make sure that they take into battle the core of loyalists that this era has bequeathed them. But since neither party's core support or base is big enough to assure victory, each struggles valiantly to make more of it—in the first instance, by growing the groups that are the most loyal, by fanning the passions on each party's lead issues to achieve even greater unity in their voting and more energy and greater turnout at the polls (2005, pp. 91-92).

The theoretical results we have presented are exactly in tune with the arguments advanced by the political professionals quoted above. By shifting their policies away from the median voter's position in the direction of their partisan constituency's policy preferences, candidates increase the unity in their partisan ranks, as Greenberg emphasizes, and candidates simultaneously energize their base to turn out to vote, as both Dowd and Greenberg emphasize. The importance of our theoretical arguments is that they illuminate why the turnout gains that candidates obtain from targeting their base are likely to outweigh the vote losses among moderate voters that noncentrist positioning would seem to entail. In particular, in a partisan electorate, voters' candidate preferences are rarely in doubt—so that moderate Democratic and Republican partisans will support their party's candidate at high rates even when these candidates propose radical positions-which give candidates the leeway to shift away from the center, in order to boost turnout among their core supporters. Thus we have shown that the strategic logic of candidate positioning in a partisan electorate with variable turnout is dramatically different from the strategic logic that obtains when we disregard voters' partisan loyalties (cf. Hinich and Ordeshook 1970). And, most importantly we have been able to account for the seemingly counterintuitive, but empirically observed, phenomenon that, even though candidates of both parties adjust their politics slightly away from national party positions to more closely fit the ideological distribution in the district being contested, in closely competitive districts Republican and Democratic candidates are just as far away from one another (or even further) than they are in highly homogenous districts that tend to be safe for the candidates of one party or the other.

Acknowledgements We are indebted to William Koetzle for providing us access to data on district demographic homogeneity, and to Keith Poole for making available to us Poole-Rosenthal DW-NOMINATE data for the House for the period of interest. We thank Dan Butler for helpful comments on the manuscript. We also owe special thanks to Clark Bensen of POLIDATA who routinely provides us with high quality data. We are indebted to Clover Behrend for bibliographic assistance. The listing of authors is alphabetical.

${ }^{17}$ This remark is also quoted in Peress (2008). 
Open Access This article is distributed under the terms of the Creative Commons Attribution Noncommercial License which permits any noncommercial use, distribution, and reproduction in any medium, provided the original author(s) and source are credited.

\section{Appendix}

Theorem 1 (The Partisan Polarization Result) When the candidates select their positions from a finite set of platforms $Z$ that includes the platforms $D_{0}$ and $R_{0}$ whose positions are given by (1)-(2) below, then, for a sufficiently small and positive value of the policy salience coefficient $a$, the equilibrium configuration in candidates' margin-maximizing strategies is $\left(D_{0}, R_{0}\right)$, where

$$
\begin{aligned}
& D_{0}=c_{D} \mu_{D}, \quad \text { where } c_{D}=\frac{e^{A}\left(e^{b}-1\right) m_{D}}{e^{A}\left(e^{b}-1\right) m_{D}+\frac{\left(e^{b}-1\right)^{2} m_{I}}{\left(2+e^{A}\right)}+\left(e^{A}+2 e^{b}\right)}, \\
& R_{0}=c_{R} \mu_{R}, \quad \text { where } c_{R}=\frac{e^{A}\left(e^{b}-1\right) m_{R}}{e^{A}\left(e^{b}-1\right) m_{R}+\frac{\left(e^{b}-1\right)^{2} m_{I}}{\left(2+e^{A}\right)}+\left(e^{A}+2 e^{b}\right)}
\end{aligned}
$$

and, $A$ is the deterministic component of the alienation threshold, $b$ is the strength of voters' partisan identification, $m_{D}, m_{R}$, and $m_{I}$ represent the proportions of Democrats, Republicans, and independents in the electorate, respectively, and $\mu_{D}$ and $\mu_{R}$ represent the mean positions of the Democratic and Republican partisan constituencies, respectively.

Proof We first prove that the derivative of candidate $D$ 's expected vote margin, $\operatorname{EM}(D)$, with respect to the ideology salience coefficient $a$, evaluated at $a=0$, achieves a maximum when $D$ 's position $D$ assumes the value $D_{0}$ given by (1) (a similar proof establishes (2)). Let $P_{k j}$ be the probability that a partisan of party $j$ (where $j=I$ denotes that the voter is an independent) votes for candidate $k$, where $j=I, D, R$ and $k=D, R$. Then for $a=0$

$$
P_{D D}=P_{R R}=\frac{e^{b}}{e^{b}+e^{A}+1} ; \quad P_{D R}=P_{R D}=\frac{1}{e^{b}+e^{A}+1} ; \quad P_{D I}=P_{R I}=\frac{1}{2+e^{A}} .
$$

$\left.\frac{\partial E M(D)}{\partial a}\right|_{a=0}$ achieves a maximum for:

$$
\begin{aligned}
& D= \frac{\left[P_{D D}\left(1-P_{D D}\right)+P_{D D} P_{R D}\right] m_{D} \mu_{D}+\left[P_{D R}\left(1-P_{D R}\right)+P_{D R} P_{R R}\right] m_{R} \mu_{R}+\left[P_{D I}\left(1-P_{D I}\right)+P_{D I} P_{R I}\right] m_{I} \mu_{I}}{\left[P_{D D}\left(1-P_{D D}\right)+P_{D D} P_{R D}\right] m_{D}+\left[P_{D R}\left(1-P_{D R}\right)+P_{D R} P_{R R}\right] m_{R}+\left[P_{D I}\left(1-P_{D I}\right)+P_{D I} P_{R I}\right] m_{I}} \\
&= \frac{\frac{e^{b}\left(e^{A}+1\right)+e^{b}}{\left(e^{b}+e^{A}+1\right)^{2}} m_{D} \mu_{D}+\frac{e^{b}+e^{A}+e^{b}}{\left(e^{b}+e^{A}+1\right)^{2}} m_{R} \mu_{R}+\frac{1+e^{A}+1}{\left(2+e^{A}\right)^{2}} m_{I} \mu_{I}}{\frac{e^{b}\left(e^{A}+1\right)+e^{b}}{\left(e^{b}+e^{A}+1\right)^{2}} m_{D}+\frac{e^{b}+e^{A}+e^{b}}{\left(e^{b}+e^{A}+1\right)^{2}} m_{R}+\frac{1+e^{A}+1}{\left(2+e^{A}\right)^{2}} m_{I}} \\
&= \frac{\frac{e^{b}\left(e^{A}+1\right)+e^{b}}{\left(e^{b}+e^{A}+1\right)^{2}} m_{D} \mu_{D}+\frac{e^{b}+e^{A}+e^{b}}{\left(e^{b}+e^{A}+1\right)^{2}} m_{R} \mu_{R}+\frac{1+e^{A}+1}{\left(2+e^{A}\right)^{2}} m_{I} \mu_{I}}{\frac{e^{b}\left(e^{A}+1\right)+e^{b}}{\left(e^{b}+e^{A}+1\right)^{2}} m_{D}+\frac{e^{b}+e^{A}+e^{b}}{\left(e^{b}+e^{A}+1\right)^{2}} m_{R}+\frac{1+e^{A}+1}{\left(2+e^{A}\right)^{2}} m_{I}} \\
&= \frac{\left[\left(e^{A+b}+2 e^{b}\right]\left(2+e^{A}\right)\right.}{\left(e^{b}+e^{A}+1\right)^{2}\left(2+e^{A}\right)} m_{D} \mu_{D}+\frac{\left(e^{A}+2 e^{b}\right)\left(2+e^{A}\right)}{\left(e^{b}+e^{A}+1\right)^{2}\left(2+e^{A}\right)} m_{R} \mu_{R}+\frac{\left(e^{b}+e^{A}+1\right)^{2}}{\left(e^{b}+e^{A}+1\right)^{2}\left(2+e^{A}\right)} m_{I} \mu_{I} \\
& \frac{\left[\left(e^{A+b}+2 e^{b}\right]\left(2+e^{A}\right)\right.}{\left(e^{b}+e^{A}+1\right)^{2}\left(2+e^{A}\right)} m_{D}+\frac{\left(e^{A}+2 e^{b}\right)\left(2+e^{A}\right)}{\left(e^{b}+e^{A}+1\right)^{2}\left(2+e^{A}\right)} m_{R}+\frac{\left(e^{b}+e^{A}+1\right)^{2}}{\left(e^{b}+e^{A}+1\right)^{2}\left(2+e^{A}\right)} m_{I}
\end{aligned}
$$




$$
\begin{aligned}
& =\frac{\left[\left(e^{A+b}+2 e^{b}\right]\left(2+e^{A}\right) m_{D} \mu_{D}+\left(e^{A}+2 e^{b}\right)\left(2+e^{A}\right) m_{R} \mu_{R}+\left(e^{b}+e^{A}+1\right)^{2} m_{I} \mu_{I}\right.}{\left[\left(e^{A+b}+2 e^{b}\right]\left(2+e^{A}\right) m_{D}+\left(e^{A}+2 e^{b}\right)\left(2+e^{A}\right) m_{R}+\left(e^{b}+e^{A}+1\right)^{2} m_{I}\right.} \\
& =\frac{\left[\left(e^{A+b}+2 e^{b}\right]\left(2+e^{A}\right) m_{D} \mu_{D}+\left(e^{A}+2 e^{b}\right)\left(2+e^{A}\right) m_{R} \mu_{R}\right.}{\left[\left(e^{A+b}+2 e^{b}\right]\left(2+e^{A}\right) m_{D}+\left(e^{A}+2 e^{b}\right)\left(2+e^{A}\right) m_{R}+\left(e^{b}+e^{A}+1\right)^{2} m_{I}\right.}
\end{aligned}
$$

because $\mu_{I}=0$.

$$
\begin{aligned}
D & =\frac{\left[\left(e^{A+b}+2 e^{b}-\left(e^{A}+2 e^{b}\right)\right]\left(2+e^{A}\right) m_{D} \mu_{D}+\left(e^{A}+2 e^{b}\right)\left(2+e^{A}\right)\left(m_{R} \mu_{R}+m_{D} \mu_{D}\right)\right.}{\left[\left(e^{A+b}+2 e^{b}\right]\left(2+e^{A}\right) m_{D}+\left(e^{A}+2 e^{b}\right)\left(2+e^{A}\right) m_{R}+\left(e^{b}+e^{A}+1\right)^{2} m_{I}\right.} \\
& =\frac{\left[\left(e^{A+b}+2 e^{b}-\left(e^{A}+2 e^{b}\right)\right]\left(2+e^{A}\right) m_{D} \mu_{D}\right.}{\left[\left(e^{A+b}+2 e^{b}\right]\left(2+e^{A}\right) m_{D}+\left(e^{A}+2 e^{b}\right)\left(2+e^{A}\right) m_{R}+\left(e^{b}+e^{A}+1\right)^{2} m_{I}\right.}
\end{aligned}
$$

because $m_{D} \mu_{D}+m_{R} \mu_{R}=0$. Making use of the equality $m_{R}=1-m_{D}-m_{I}$, we see that $\left.\frac{\partial E M(D)}{\partial a}\right|_{a=0}$ achieves a maximum for:

$$
D=\frac{e^{A}\left(e^{b}-1\right)\left(2+e^{A}\right) m_{D} \mu_{D}}{e^{A}\left(e^{b}-1\right)\left(2+e^{A}\right) m_{D}+\left(e^{b}-1\right)^{2} m_{I}+\left(e^{A}+2 e^{b}\right)\left(2+e^{A}\right)}
$$

which is equivalent to the form given in (1). This demonstrates that as a policy component is introduced into the model-i.e., as the value of $a$ increases from zero to a small positive value-candidate $D$ 's expected vote margin $\operatorname{EM}(D, a)$ increases most rapidly as a function of $a$ for the strategy $D_{0}$. Because $\operatorname{EM}(D, 0)$ is identical for all $D$, this in turn implies that for any two policy platforms $D_{0}$ and $D_{1}$ (where $D_{0} \neq D_{1}$ ), there is some positive value of the ideology-salience coefficient $a\left(D_{1}\right)$-which depends on the platform $D_{1}$-such that $\operatorname{EM}\left(D_{0}, a\right)>\operatorname{EM}\left(D_{1}, a\right)$ for any $a, 0<a<a\left(D_{1}\right)$. With candidate $R$ fixed at his equilibrium position, let $a_{m D}$ be the smallest value of $a\left(D_{1}\right)$ for $D_{1} \in Z$ (with $D_{1} \neq D_{0}$ ). Thus, for $0<a<a_{m D}, \operatorname{EM}\left(D_{0}, a\right)>E M\left(D_{1}, a\right)$ for $D_{1} \in Z$ (with $D_{1} \neq D_{0}$ ). It follows that for $0<a<a_{m D}$, candidate $D$ 's margin-maximizing position is $D_{0}$, no matter which platform $R \in Z$ candidate $R$ selects. We can use the identical approach to specify the value $a_{m R}$ such that when $0<a<a_{m R}$, candidate $R$ 's margin-maximizing position is $R_{0}$, no matter which platform $D \in P$ candidate $D$ selects. It then follows that for $0<a<\min \left(a_{m R}, a_{m D}\right)$, the equilibrium configuration in candidates' margin-maximizing strategies is $\left(D_{0}, R_{0}\right)$. This completes the proof of Theorem 1 .

Corollary to Theorem 1 (The Polarization Gap) For the conditions specified in Theorem 1 , then, for a fixed proportion $m_{I}$ of independent voters, the divergence between the candidates' equilibrium positions is greatest when the Democratic and Republican partisan constituencies are of equal size, i.e., when $m_{D}=m_{R}$, and the degree of divergence declines monotonically as $\left(m_{D}-m_{R}\right)$ diverges from zero.

Proof Note first that it follows from (1) that candidate $D$ 's degree of equilibrium divergence from the mean voter position $\mu_{V}=0$ is a strictly concave function of $m_{D}$, so that $D$ 's equilibrium position diverges from $\mu_{V}=0$ at an ever decreasing rate as $m_{D}$ increases. ${ }^{18}$

\footnotetext{
${ }^{18}$ This follows from the fact that the numerator in (1) is a linear function of $m_{D}$, as is the first expression in the denominator of (1), while there are additional terms in the denominator that are positive.
} 
Similarly, it follows from (2) that candidate $R$ 's degree of divergence from $\mu_{V}=0$ is a strictly concave function of $m_{R}$. Defining

$$
f(x)=\frac{e^{A}\left(e^{b}-1\right) x}{e^{A}\left(e^{b}-1\right) x+\frac{\left(e^{b}-1\right)^{2} m_{I}}{\left(2+e^{A}\right)}+\left(e^{A}+2 e^{b}\right)},
$$

so that $c_{D}=f\left(m_{D}\right)$ and $c_{R}=f\left(m_{R}\right)$, we have

$$
\frac{\partial(R-D)}{\partial m_{D}}=\frac{\partial f}{\partial m_{D}}\left(1-m_{D}-m_{I}\right) \mu_{R}-\frac{\partial f}{\partial m_{D}}\left(m_{D}\right) \mu_{D} .
$$

The divergence between the candidates, $(R-D)$, has a critical point when $\frac{\partial(R-D)}{\partial m_{D}}=0$, i.e., when

$$
\frac{\partial f}{\partial m_{D}}\left(m_{D}\right) \mu_{D}=-\frac{\partial f}{\partial m_{D}}\left(m_{R}\right) \mu_{R}
$$

But given that $\mu_{V}=m_{D} \mu_{D}+m_{R} \mu_{R}+m_{I} \mu_{I}=0$ and $\mu_{I}=0$, it follows that $\mu_{R}=-\frac{m_{D} \mu_{D}}{m_{R}}$, so that

$$
\frac{\partial f}{\partial m_{D}}\left(m_{D}\right) \mu_{D}=\frac{\partial f}{\partial m_{D}}\left(m_{R}\right) \frac{m_{D} \mu_{D}}{m_{R}},
$$

i.e.,

$$
\frac{\partial f}{\partial m_{D}}\left(m_{D}\right) m_{R}=\frac{\partial f}{\partial m_{D}}\left(m_{R}\right) m_{D},
$$

which in turn holds if and only if $m_{D}=m_{R}$. To see this, note that clearly, equality holds if $m_{D}=m_{R}$. If not, since $f$ is strictly concave in $m_{D}, \frac{\partial f}{\partial m_{D}}$ is strictly decreasing in $m_{D}$, so that if, say, $m_{D}<m_{R}$, then $\frac{\partial f}{\partial m_{D}}\left(m_{D}\right)>\frac{\partial f}{\partial m_{D}}\left(m_{R}\right)$ and $m_{R}>m_{D}$, so that $\frac{\partial f}{\partial m_{D}}\left(m_{D}\right) m_{R}>\frac{\partial f}{\partial m_{D}}\left(m_{R}\right) m_{D}$. Similarly, if $m_{D}>m_{R}$, then $\frac{\partial f}{\partial m_{D}}\left(m_{D}\right) m_{R}<\frac{\partial f}{\partial m_{D}}\left(m_{R}\right) m_{D}$. It follows from these same inequalities that $\frac{\partial(R-D)}{\partial m_{D}}$ is positive to the left of $m_{D}=m_{R}$ and negative to the right so that this critical point is a maximum for $(R-D)$ and the expression $(R-D)$ declines monotonically on each side of the point where $m_{D}=m_{R}$. Thus, for a fixed proportion $m_{I}$ of independent voters, the maximum divergence between the candidates' equilibrium positions occurs when $m_{D}=m_{R}$, and the degree of divergence declines monotonically as $\left(m_{D}-m_{R}\right)$ diverges from zero.

\section{References}

Adams, J., \& Merrill, S., III (2008). Candidate and party strategies and two-stage elections beginning with a primary. American Journal of Political Science, 52(2), 344-359.

Adams, J., Bishin, B., \& Dow, J. K. (2004). Representation in congressional campaigns: evidence for directional/discounting motivations in United States senate elections. Journal of Politics, 66(2), 348-373.

Adams, J., Merrill, S., III, \& Grofman, B. (2005). A unified theory of party competition: a cross-national analysis integrating spatial and behavioral factors. Cambridge: Cambridge University Press.

Adams, J., Dow, J. K., \& Merrill, S., III (2006). The political consequences of alienation-based and indifference-based voter abstention: applications to presidential elections. Political Behavior, 28(1), 6586.

Aldrich, J. (1995). Why parties? The origins and transformation of party politics in America. Chicago: University of Chicago Press.

Alvarez, R. M., \& Nagler, J. (1995). Economics, issues, and the Perot candidacy: voter choice in the 1992 presidential election. American Journal of Political Science, 39, 714-744. 
Alvarez, R. M., \& Nagler, J. (1998). When politics and models collide: estimating models of multiparty elections. American Journal of Political Science, 42, 55-96.

Anderson, S., \& Glomm, G. (1992). Alienation, indifference, and the choice of ideological position. Social Choice and Welfare, 9, 17-31.

Ansolabehere, S., Snyder, J., \& Stewart, C. (2001). Candidate positioning in US House elections. American Journal of Political Science, 45, 136-159.

Baughman, J. (2004). Party, constituency and representation: votes on abortion in the British House of Commons. Public Choice, 120, 63-85.

Bishin, B. (2000). Constituency influence in Congress: does subconstituency matter? Legislative Studies Quarterly, 25, 389-415.

Bishin, B. (2009). Tyranny of the minority: the subconstituency politics theory of representation. Philadelphia: Temple University Press.

Brody, R., \& Page, B. (1973). Indifference, alienation, and rational decisions: the effects of candidate evaluation on turnout and the vote. Public Choice, 15, 1-17.

Burden, B. (2001). The polarizing effects of congressional elections. In P. F. Galderisi, M. Ezra, \& M. Lyons (Eds.), Congressional primaries and the politics of representation. Totowa: Rowman and Littlefield.

Burden, B., \& Lacy, L. (1999). The vote-stealing and turnout effects of third-party candidates in US presidential elections, 1968-1996. Presented at the annual meeting of the American Political Science Association, Atlanta, GA.

Butler, D. (2006). Explaining the increased polarization in the US Congress. Typescript.

Callander, S., \& Wilson, C. (2006). Context-dependent voting. Quarterly Journal of Political Science, 1(3), 227-254.

Campbell, A., Converse, P. E., Miller, W. E., \& Stokes, D. E. (1960). The American voter. New York: Wiley.

Clinton, J. D. (2006). Representation in Congress: constituents and roll calls in the 106th House. Journal of Politics, 68(2), 397-409.

Clinton, J. D., Jackman, S., \& Rivers, D. (2004). The statistical analysis of legislative behavior: a unified approach. American Political Science Review, 98(2), 355-370.

Downs, A. (1957). An economic theory of democracy. New York: Harper and Row.

Endersby, J., \& Galatas, S. (1998). British parties and spatial competition: dimensions of evaluation in the 1992 election. Public Choice, 97, 363-382.

Enelow, J. M., \& Hinich, M. J. (1989). A general probabilistic spatial theory of elections. Public Choice, 61(2), 101-113.

Erikson, R., \& Romero, D. (1990). Candidate equilibrium and the behavioral model of the vote. American Political Science Review, 84, 1103-1126.

Erikson, R., \& Wright, G. (1997). Voters, candidates, and issues in congressional elections. In L. Dodd \& B. Oppenheimer (Eds.), Congress reconsidered (6th ed.). Washington: Congressional Quarterly Press.

Erikson, R., \& Wright, G. (2000). Representation of constituency ideology in congress. In D. Brady, J. Cogan, \& M. Fiorina (Eds.), Continuity and change in House elections. Stanford: Stanford University Press.

Fenno, R. F. (1978). Home style: house members in their districts. Boston: Little Brown.

Fiorina, M. (1981). Retrospective voting in American national elections. New Haven: Yale University Press.

Green, D., Palmquist, B., \& Schickler, E. (2002). Partisan hearts and minds: political parties and the social identities of voters. New Haven: Yale University Press.

Grofman, B. (2004). Downs and two-party convergence. Annual Review of Political Science, 7, 25-46. Polsby, N. (Ed.).

Groseclose, T., \& Snyder, J. M. (2000). Estimating party influence in congressional roll-call voting. American Journal of Political Science, 44, 187-205.

Guttman, J. M., Hilger, N., \& Shachmurove, Y. (1994). Voting as investment vs. voting as consumption-new evidence. Kyklos, 47(2), 197-207.

Heckman, J. J., \& Snyder, J. M. (1997). Linear probability models of the demand for attributes with an empirical application to estimating the preferences of legislators. Rand Journal of Economics, 28, 142189.

Hinich, M., \& Ordeshook, P. (1970). Plurality maximization versus vote maximization: a spatial analysis with variable participation. American Political Science Review, 64(3), 772-791.

Jennings, K., \& Niemi, R. (1981). Generations and politics. Princeton: Princeton University Press.

Kenny, L., \& Lotfinia, B. (2005). Evidence on the importance of spatial models in presidential nominations and elections. Public Choice, 123(3), 439-462.

Key, V. O. (1947). Politics, parties, and pressure groups. New York: Crowell Company.

Krasno, J. S. (1994). Challengers, competition, and reelection: comparing Senate and House Elections. New Haven: Yale University Press.

Lacy, D., \& Paolino, P. (1998). Downsian voting and separation of powers. American Journal of Political Science, 42, 1180-1199. 
Lee, D. S., Moretti, E., \& Butler, M. J. (2004). Do voters affect or elect policies? Evidence from the US House. Quarterly Journal of Economics, 119(3), 807-859.

Markus, G. A., \& Converse, P. E. (1979). A dynamic simultaneous equation model of electoral choice. American Political Science Review, 73, 1055-1070.

McIver, J. P., Erikson, R. S., \& Wright, G. C. (1993). Public opinion and public policy: a view from the states. In Dodd, L. C., \& Jillson, C. (Eds.), New perspectives on American politics. Washington: Congressional Quarterly Press.

Merrill, S., III, \& Adams, J. (2002). Centrifugal incentives in multicandidate elections. Journal of Theoretical Politics, 14(3), 275-300.

Millbank, D., \& Allen, M. (2004). Bush fortifies conservative base: campaign seeks solid support before wooing swing voters. Washington Post, July 15.

Miller, G., \& Schofield, N. (2003). Activists and partisan realignment in the United States. American Political Science Review, 97, 245-260.

Miller, W., \& Stokes, D. (1963). Constituency influence in Congress. American Political Science Review, $57(1), 45-56$.

Miniter, B. (2005). The McCain myth: the moderation that makes him a Senate powerhouse will keep him out of the White House. Wall Street Journal, May 31.

Nagourney, A. (2003). Political parties shift emphases to core voters. New York Times, August 30.

Owen, G., \& Grofman, B. (2006). Two-stage electoral competition in two-party contests: persistent divergence of party positions. Social Choice and Welfare, 26(3), 547-569.

Palfrey, T. (1984). Spatial equilibrium with entry. Review of Economic Studies, 51, 139-151.

Peress, M. (2008). Securing the base: electoral competition under variable turnout (Typescript). University of Rochester.

Polsby, N. W. (1983). Consequences of party reform. London: Oxford University Press.

Poole, K., \& Rosenthal, H. (1984). The polarization of American politics. Journal of Politics, 46, 1061-1079.

Roemer, J. (2001). Political competition: theory and applications. Cambridge: Harvard University Press.

Schmidt, A., Kenny, L., \& Morton, R. (1996). Evidence of electoral accountability in the US Senate: are unfaithful agents really punished? Economic Enquiry, 34, 545-567.

Schofield, N. (2004). Equilibrium in the spatial 'valence' model of politics. Journal of Theoretical Politics, $16,447-481$.

Schofield, N., \& Sened, I. (2005). Modeling the interaction of parties, activists and voters: why is the political center so empty? European Journal of Political Research, 44(3), 355-390.

Schofield, N., \& Sened, I. (2006). Multiparty democracy: elections and legislative politics. Cambridge: Cambridge University Press.

Serra, G. (2008). Polarization of what? A model of elections with endogenous Valence. Presented at the annual meeting of the American Political Science Association, Boston, MA, September 2008.

Snyder, J. (1994). Safe seats, marginal seats, and party platforms: the logic of party differentiation. Economics and Politics, 6(3), 201-213.

Stone, W., \& Simas, E. (2008). Candidate valence and ideological positions in the 2006 elections (Typescript).

Toner, R. (2004). Political memo. New York Times, p. 141, 19 December 2004.

Uslaner, E. M. (1999). The movers and the shirkers: representatives and ideologues in the Senate. Ann Arbor: University of Michigan Press.

Van Houweling, R. P., \& Sniderman, P. M. (2005). The political logic of a Downsian space (Working paper). 